\title{
QUALIDADE DE ÁGUA DE DESSEDENTAÇÃO DE BOVINOS DA FAZENDA-ESCOLA DO IFRN-IPANGUAÇU
}

\author{
S. B. N. NETO, I. I. M. ARAÚJO e M. A. TÁVORA \\ Instituto Federal do Rio Grande do Norte - IFRN \\ marcelo.tavora@ifrn.edu.br*
}

Artigo submetido em fevereiro/2016 e aceito em abril/2016

DOI: $10.15628 /$ holos.2016.4150

\section{RESUMO}

Na produção animal, é de fundamental importância o uso racional da água de boa qualidade. A água deve ser considerada como um nutriente essencial e quando a qualidade utilizada na dessedentação animal for duvidosa, esta pode interferir nos índices zootécnicos e na disseminação de enfermidades, acarretando graves prejuízos econômicos. Objetivou-se com esta pesquisa diagnosticar a qualidade da água que é ofertada para dessedentação dos bovinos de leite da Fazenda-escola do IFRN, campus Ipanguaçu. As coletas e análises foram realizadas quinzenalmente nos bebedouros dos bovinos (no total, seis bebedouros) durante os meses de Junho à Setembro de 2015. Os parâmetros analisados foram: temperatura, $\mathrm{pH}$, condutividade, oxigênio dissolvido e sólidos totais dissolvidos; utilizando uma sonda multiparamétrica de qualidade de água. Os dados obtidos revelaram que os parâmetros, exceto sólidos totais dissolvidos, encontraram-se nos limites aceitáveis pela resolução CONAMA 357/2005, com alguns bebedouros apresentando resultados não aceitáveis. Contudo, é preciso ainda um manejo adequado da água (com renovação constante) e bebedouros que estejam dispostos não apenas em locais de fácil acesso aos animais, mas que também possam estar em locais cobertos ou arejados por copa de árvores.

PALAVRAS-CHAVE: Nutrição animal, produção animal, índices zootécnicos.

\section{WATERING WATER QUALITY BOVINE IN SCHOOL-FARM AT IFRN-IPANGUAÇU}

\begin{abstract}
In animal production, it is of fundamental importance the rational use of good quality water. Water should be considered as an essential nutrient and when the quality used in animal consumption is doubtful, this can interfere with the performance parameters and the spread of diseases, causing serious economic losses. The objective of this research to diagnose the quality of water that is supplied to the watering water quality bovine in schoolfarm at IFRN-Ipanguaçu. Sampling and analyzes were carried out fortnightly in the water drinker of bovine (a total of six drinking fountains) during the months of June
\end{abstract}

to September 2015. The parameters analyzed were: temperature, $\mathrm{pH}$, conductivity, dissolved oxygen and total dissolved solids; using a multi-parameter explorer water quality. The data revealed that the parameters except total dissolved solids, met the limits acceptable by Resolution CONAMA 357/2005, with occasional drinkers presenting unacceptable results. However, it is also necessary to a proper water management (with constant renewal) and drinkers who are willing not only in readily accessible to animals, but they can also be in local or airy covered by tree canopy.

KEYWORDS: Animal nutrition, animal production, zootechnical indexes. 


\section{INTRODUÇÃO}

A água é um recurso natural fundamental para produção animal, devendo estar disponível em quantidade e qualidade. Ela é utilizada tanto na dessedentação dos animais como na higienização das instalações.

De acordo com MARIA \& ALBERTO (2009), para ter uma produção animal de qualidade deve se dar à água uma importância semelhante a que se dá a outros fatores de produção como instalações e manejo.

De acordo com GREIF (2006), deve-se considerar a água utilizada para dessedentação de animais na questão qualidade e quantidade de água consumida em $L$ unidade- 1 dia-1. Por exemplo: o consumo de água pelos bovinos é de 50 , bubalinos 60 , equinos 40 , ovinos 7 , suínos 20 , caprinos 7 e aves 0,36 L unidade- 1 dia-1. Fora isto, a água também é utilizada no processamento de carcaças nos abatedouros e matadouros, locais onde são gerados impactos negativos e aonde este recurso precisa ser tratado previamente antes de ser lançado ao ambiente.

A água é um recurso natural que já apresenta escasso em várias partes do mundo, inclusive no Brasil. Em vista disso, o Brasil determinou em sua Política Nacional dos Recursos Hídricos que a "água é um bem de domínio público e um recurso limitado, dotado de valor econômico". Com isso, a exigência de atitudes conservacionistas para com este recurso natural será cada vez mais exigida pela sociedade, devendo as cadeias produtivas estar cientes deste fato (PALHARES, 2008).

No município de Ipanguaçu-RN, localizado no vale do açu, à $220 \mathrm{~km}$ de Natal, não tem sido diferente. O principal recurso hídrico da região, rio piranhas-açu, apresenta-se com baixa vazão e a barragem Armando Ribeiro Gonçalves encontra-se em nível muito baixo, fazendo com que as práticas conservacionistas sejam amplamente difundidas. Devido às errôneas práticas de utilização da bacia hidrográfica, a qualidade de água superficial disponível tem sido comprometida, possibilitando a ocorrência de prejuízos às atividades produtivas, como a criação de gado de leite.

O conhecimento sobre a qualidade da água ofertada para os bovinos é de suma importância diante do cenário de produção agropecuária. Deve ser dada atenção aos critérios da qualidade da água, pois é um dos fatores que influencia a ingestão desse recurso natural e está altamente correlacionado com diversos fatores que influenciam no bem estar animal, além de ser um recurso natural atualmente de escassa qualidade disponível na dessedentação animal. Assim, a água é um recurso natural tão importante quanto carboidratos, proteínas, minerais e vitaminas, e o seu estudo deve estar presente nas pesquisas atuais e futuras para que sua importância seja sempre destacada e conhecida.

Diante disso, o referido projeto será desenvolvido na fazenda-escola do IFRN campus de Ipanguaçu, construída para ser um modelo de agropecuária para o vale do Açu. A fazenda-escola possui área de 127 ha, sendo 30 ha de reserva legal. A fazenda é abastecida por poços (amazonas e tubulares), que ofertam água para dessedentação dos animais.

Dessa forma, o objetivo é diagnosticar a qualidade de água que é ofertada para dessedentação de bovinos na fazenda-escola do IFRN campus Ipanguaçu. 


\section{REVISÃO BIBLIOGRÁFICA}

Para o termo "qualidade da água" é necessário compreender que este não se refere necessariamente a um estado de pureza, mas às características químicas, físicas e biológicas e que, conforme essas características são estipuladas diferentes finalidades para a água (MERTEN \& MINELLA, 2002).

Dados do IEPEC (2008) destacam como uma água de baixa qualidade aquela que apresenta elevada acidez, elevada alcalinidade, presença de sulfetos de hidrogênio, presença de sulfatos de ferro e manganês e alto conteúdo de sólidos totais dissolvidos. Com relação à poluição destacam alta contagem de bactérias (coliformes fecais ou não, Streptococcus, Pseudomonas), população elevada de algas verdes e azuis, presença de produtos químicos.

Atualmente, tem-se preocupado com a qualidade da água e o seu reflexo com o desempenho animal. Vários países adotaram guias de qualidade da água para animais de produção como o Canadá (Canadian Council of Ministries of Environmente - CCME) e Austrália e Nova Zelândia (Austrália and New Zealand Environment and Conservation Council - ANZECC) (DIAS, 2006). No Brasil, existem diversos parâmetros de qualidade de água a serem respeitados. A resolução normativa no 357 do CONAMA (BRASIL, 2005) estabelece a classificação das águas, segundo a sua utilização, definindo parâmetros de qualidade a serem atendidos.

A classificação das águas segundo o Conselho Nacional do Meio Ambiente (CONAMA) em sua resolução no 357/2005, classifica os recursos hídricos, segundo seus usos preponderantes, em classes a saber:

Águas Doces: Classe Especial (para abastecimento doméstico sem prévia ou com desinfecção simplificada; para a preservação do equilíbrio natural das espécies aquáticas); Classe 1 (abastecimento doméstico após tratamento simplificado, proteção de comunidades aquáticas, irrigação de frutas e hortaliças consumidas cruas, recreação de contato primário, aqüicultura); Classe 2 (abastecimento doméstico após tratamento convencional, proteção de comunidades aquáticas, recreação de contato primário, aqüicultura); Classe 3 (abastecimento doméstico após tratamento convencional, irrigação de culturas arbóreas, cerealíferas e forrageiras, dessedentação animal); Classe 4 (navegação); Águas Salobras: Classe 7 (recreação de contato primário, proteção de comunidades aquáticas, aqüicultura), Classe 8 (navegação comercial, harmonia paisagística, recreação de contato secundário, segundo (BRASIL, 2005).

Segundo a Resolução CONAMA no 357/2005 (BRASIL, 2005), "a qualidade da água de dessedentação dos animais de produção devem ser tratada de forma específica, com o estabelecimento de concentrações para este tipo de água". E ainda, "as águas destinadas à dessedentação animal devem estar dentro dos padrões exigidos para Classe 3", que também são "águas destinadas ao consumo humanos, após tratamento convencional ou avançado, à irrigação de culturas arbóreas, cerealíferas e forrageiras, à pesca amadora e à recreação de contato secundário".

A Declaração Universal dos Direitos da Água, em seu artigo segundo, é muito clara quando diz que a água é a seiva do planeta, ou seja, é a condição essencial de vida de todo ser vegetal, animal ou humano. Nessa visão necessitamos perceber que a mesma água que mantém nossas florestas verdes é a água que alimenta nossos animais de produção, é a água que sacia a sede do 
ser humano e viabiliza tantas outras atividades (SANTOS, 2005). No entanto, segundo este mesmo autor, de nada servirá a abundância de água se a mesma não atender a critérios rígidos de qualidade que devem levar em conta desde sua procedência até os produtos aplicados no seu tratamento.

Os bovinos de leite necessitam de um suprimento adequado de água de boa qualidade para inúmeras funções orgânicas, como: a fermentação normal do rúmen e seu metabolismo; o fluxo adequado do alimento através do trato digestório; adequada digestão e absorção dos nutrientes; volume de sangue normal e ainda, a irrigação de todos os tecidos (IEPEC, 2008).

As características que afetam a qualidade da água tornando-a imprópria para o consumo de bovinos são: presença de minerais traços tóxicos como Flúor ( $F)$, Selênio (Se), Ferro (Fe) e Molibdênio (Mb), podendo causar distúrbios sérios, principalmente em ovinos e aves; a presença de Nitrogênio na água indica decomposição de matéria orgânica, contaminação fecal ou nitratos. (DIAS, 2006)

Esses animais também demandam de outros aspectos de qualidade da água para o consumo: a água deve ser incolor, inodora e insípida para ser considerada de dessedentação para os bovinos de leite; o pH ideal é o que esteja próximo da faixa de neutralidade $(\mathrm{pH} 7,0)$ pois, valores acima de 7,6 indicam alcalinidade, podendo apresentar níveis elevados de Cálcio (Ca) e Magnésio $(\mathrm{Mg})$, tornando a água imprópria para consumo. (IEPEC, 2008)

A salinidade é o principal fator que determina se uma fonte de água é apropriada para o animal. A maioria dos sais, que são dissolvidos na água, apresenta composto inorgânico como sulfatos, cloretos, carbonatos, bicarbonatos de cálcio, magnésio e sódio. Em alguns casos estes sais podem estar presentes em excesso e causar efeitos danosos. Em geral, os animais de aptidão leiteira são mais resistentes ao excesso de sal que os animais de corte. Se a salinidade for adequada, pode ser uma boa contribuição ao consumo de minerais. (DIAS, 2006)

A salinidade refere-se à quantidade total de sais minerais dissolvidos na água e pode ser determinada como sólidos totais dissolvidos (SDT) ou como sais totais dissolvidos. Conceitualmente o SDT quantifica a soma de matéria inorgânica dissolvida em uma amostra de água (PATIENCE, 1992). Caso o nível de sais minerais dissolvidos esteja elevado, sendo superior ao nível máximo que é de 500mg/L segundo resolução CONAMA 357 (BRASIL, 2005), isso implicaria em uma diminuição no consumo de água pelos animais, acarretando alguns transtornos na dieta alimentar dos animais.

Em outras palavras, a salinidade da água pode ser avaliada pela Condutividade Elétrica. A concentração total de sais na água de dessedentação, sem especificá-los, é avaliada em relação à condutividade elétrica (CE) expressa em $\mathrm{dS} / \mathrm{m}$ ou $\mathrm{mS} / \mathrm{cm}$. Estas unidades possuem equivalência, conforme o Sistema Internacional (SI) de unidades: $1 \mathrm{dS} / \mathrm{m}=1 \mathrm{mmho} / \mathrm{cm}=1 \mathrm{mS} / \mathrm{cm}=1.000 \mathrm{uS} / \mathrm{cm}$ $=1.000$ umho/cm.

A temperatura da água de bebida é outro fator que pode interferir na ingestão de água dos bovinos. Há, porém, muita controvérsia em relação à temperatura ideal da água. Alguns trabalhos indicam que bovinos preferem água morna, cerca de $30{ }^{\circ} \mathrm{C}$, em relação a temperaturas menores (WILKS et al.,1990; OSBORNE et al., 2002). Enquanto que Anderson (1985) diz que o consumo de água por bovinos taurinos na Suécia é reduzido significativamente quando a temperatura da água é mais elevada $\left(24^{\circ} \mathrm{C}\right)$, numa escala de temperaturas de $3,10,17$ e $24^{\circ} \mathrm{C}$. Na literatura existem 
algumas variações quanto à temperatura ideal da água para bovinos, consequentemente, a temperatura pode influenciar no desempenho de ganho de peso desses animais. Por exemplo, Lardy e Stoltenow (1999) afirmam que a temperatura da água de consumo dos animais deve estar entre $4,44^{\circ} \mathrm{C}$ a $18,33^{\circ} \mathrm{C}$, pois a ingestão da água nessa temperatura acrescenta um ganho diário de peso de 0,14 a $0,18 \mathrm{Kg}$, em relação a animais que consomem água mais quente.

O oxigênio dissolvido é consumido na água especialmente pela decomposição aeróbia de compostos de carbono, mas também pela nitrificação de amônio. Concentrações baixas de oxigênio indicam a presença de substâncias que foram lançadas na água ou surgiram como carga secundária (plantas e algas aquáticas em fase de decomposição, biofilmes, etc.).

A temperatura da água é importante para o animal, pois quando ofertada em condições propícias, auxilia na digestão dos ruminantes. Ademais, temperaturas elevadas oportunizam a proliferação de micro-organismos patogênicos. Para Lejeune et al. (2001), a exposição diária a micro-organismos patogênicos por meio da água de bebedouro pode ser prejudicial à saúde dos animais e que o grau de contaminação dos bebedouros bovinos relaciona-se diretamente com proximidade do local de alimentação, tipo de cobertura e período de temperatura mais elevada.

\section{MATERIAIS E MÉTODOS}

Para avaliar a qualidade da água que é ofertada para dessedentação dos bovinos de leite da Fazenda-escola do Instituto Federal do Rio Grande do Norte - IFRN, no município de Ipanguaçu, foram realizadas análises da água nos bebedouros. O setor de bovinocultura possui seis bebedouros disponíveis para os animais. (Figura 1)

a)

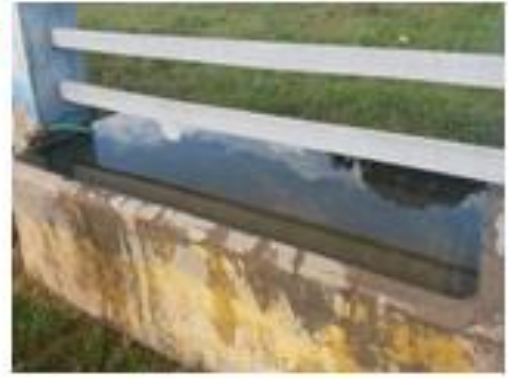

d)

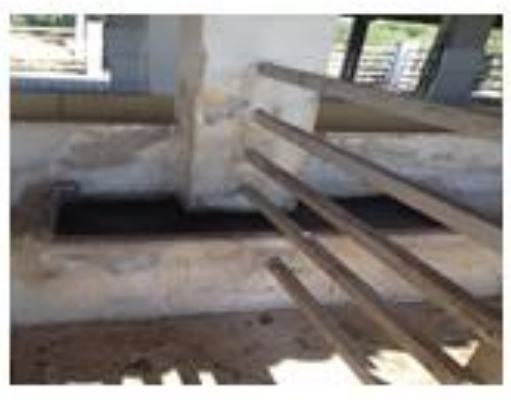

b)

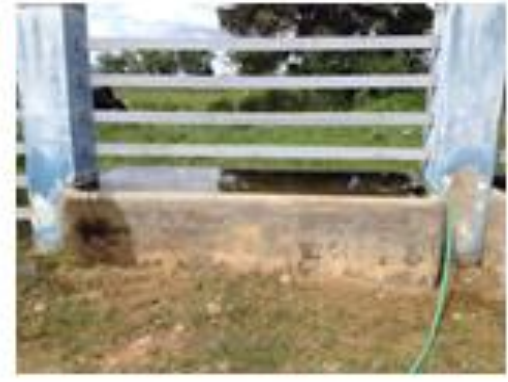

e)

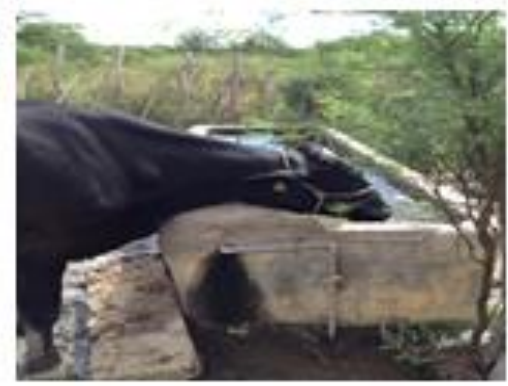

c)

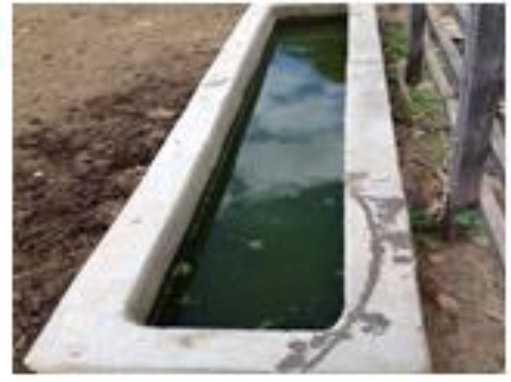

f)

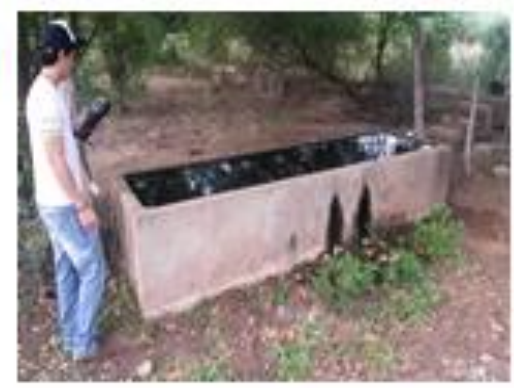

Figura 1: Bebedouros de bovinos: a) bebedouro B1, b) bebedouro B2, C) bebedouro B3, d) bebedouro B4, e) bebedouro B5 e f) bebedouro B6

Os parâmetros analisados foram: temperatura, $\mathrm{pH}$, condutividade, oxigênio dissolvido e sólidos totais dissolvidos. Para a análise desses parâmetros foi utilizada uma sonda 
multiparamétrica de qualidade de água. As análises foram realizadas quinzenalmente, de Junho à Setembro de 2015.

Os dados obtidos foram armazenados em planilha do Excel e aferido um valor médio de cada parâmetro para cada mês correspondente. Os dados foram discutidos com base no que orienta a Resolução CONAMA no 357/2005.

\section{RESULTADOS E DISCUSSÕES}

Com base nos dados obtidos na Tabela 1, é possível perceber que as temperaturas mais elevadas foram observadas nos bebedouros B1, B2, B3 e B5. Isso ocorre pelo fato que os mesmos estão expostos constantemente a luz do sol, enquanto que B4 é coberto pelo telhado do estábulo e B6 pela sombra de uma árvore, possibilitando assim, temperaturas mais baixas "in locu".

Tabela 1: Médias do parâmetro, temperatura, nos referidos meses e bebedouros.

\begin{tabular}{|c|c|c|c|c|c|}
\hline Parâmetro & Bebedouro & Junho & Julho & Agosto & Setembro \\
\hline 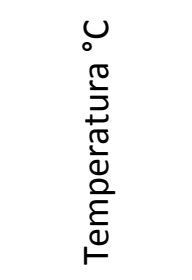 & $\begin{array}{l}\text { B1 } \\
\text { B2 } \\
\text { B3 } \\
\text { B4 } \\
\text { B5 } \\
\text { B6 }\end{array}$ & $\begin{array}{c}30,81 \\
31,44 \\
30,46 \\
26,5 \\
31,6 \\
27.03\end{array}$ & $\begin{array}{l}28,56 \\
28,27 \\
30,77 \\
28,70 \\
31,25 \\
28,74\end{array}$ & $\begin{array}{l}25,81 \\
25,68 \\
25,95 \\
24,63 \\
25,18 \\
24,52\end{array}$ & $\begin{array}{l}24,77 \\
24,77 \\
25,72 \\
24,77 \\
26,20 \\
26,93\end{array}$ \\
\hline
\end{tabular}

É importante ressaltar que temperaturas elevadas da água contribuem para a proliferação de micro-organismos patogênicos. Nogueira et al. (2003) verificaram interferência da temperatura da água na porcentagem de amostras positivas para coliformes. O número de amostras positivas tanto para coliformes totais quanto fecais diminuiu com o decréscimo da temperatura. Segundo Fransolet et al. (1985) a Escherichia coli (E. coli) tem desenvolvimento diminuído quando a temperatura da água é menor que $200 \mathrm{C}$.

Segundo a Resolução CONAMA no 357/2005, o pH aceitável para dessedentação de animais é de 6 a 9. Conforme a Tabela 2, os bebedouros B1, B2 e B3 apresentaram, nos meses de julho a setembro, valores acima do aceitável para o consumo de animais.

Valores de $\mathrm{pH}$ superiores a 9 podem provocar distúrbios digestivos e diarréias, diminuição da eficiência de conversão alimentar e redução da ingestão de alimentos. (PORTUGAL, 2015).

O oxigênio dissolvido analisado durante a pesquisa, (Tabela 3 ), apresentou valores abaixo do aceitável para ingestão de animais. 
Tabela 2: Médias do parâmetro, pH, nos referidos meses e bebedouros.

\begin{tabular}{c|c|c|c|c|c}
\hline \multirow{2}{*}{ Parâmetro } & Bebedouro & Junho & Julho & Agosto & Setembro \\
& & & & & \\
& & & & 9,24 & 10,42 \\
I & B1 & 8,97 & 9,12 & 9,06 & 8,18 \\
& B2 & 8,96 & 9,03 & 9,11 & 7,96 \\
& B3 & 8,41 & 9,18 & 8,81 & 8,13 \\
& B5 & 8,28 & 7,84 & 8,22 & \\
\hline
\end{tabular}

Tabela 3: Médias do parâmetro, oxigênio dissolvido ( $\mathrm{mg} / \mathrm{L})$, nos referidos meses e bebedouros.

\begin{tabular}{|c|c|c|c|c|c|}
\hline Parâmetro & Bebedouro & Junho & Julho & Agosto & Setembro \\
\hline 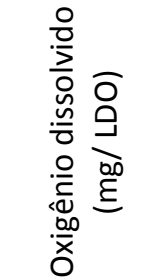 & $\begin{array}{l}\text { B1 } \\
\text { B2 } \\
\text { B3 } \\
\text { B4 } \\
\text { B5 } \\
\text { B6 }\end{array}$ & $\begin{array}{c}12,56 \\
17,43 \\
9,22 \\
4,72 \\
12,56 \\
6,42\end{array}$ & $\begin{array}{c}15,78 \\
15,87 \\
21,2 \\
9,16 \\
7,50 \\
5,72\end{array}$ & $\begin{array}{c}18,90 \\
14,47 \\
10,88 \\
10,52 \\
8,98 \\
2,76\end{array}$ & $\begin{array}{c}10,61 \\
8,36 \\
6,59 \\
3,57 \\
6,50 \\
5,76\end{array}$ \\
\hline
\end{tabular}

A Resolução CONAMA nำ37/2005 orienta que, o oxigênio dissolvido em qualquer amostra, não pode ser inferior a $4 \mathrm{mg} / \mathrm{L}$. Os bebedouros B6 e B4 apresentaram valores menores que o mínimo permitido pela resolução, em amostras de Agosto e Setembro.

O limite máximo segundo a Resolução CONAMA n³57/2005 para Sólidos dissolvidos totais é de $500 \mathrm{mg} / \mathrm{L}$, logo, todas as amostras aferidas estão acima do permitido (Tabela 4).

Tabela 4: Médias do parâmetro, sólidos totais $(\mathrm{mg} / \mathrm{L})$, nos referidos meses e bebedouros.

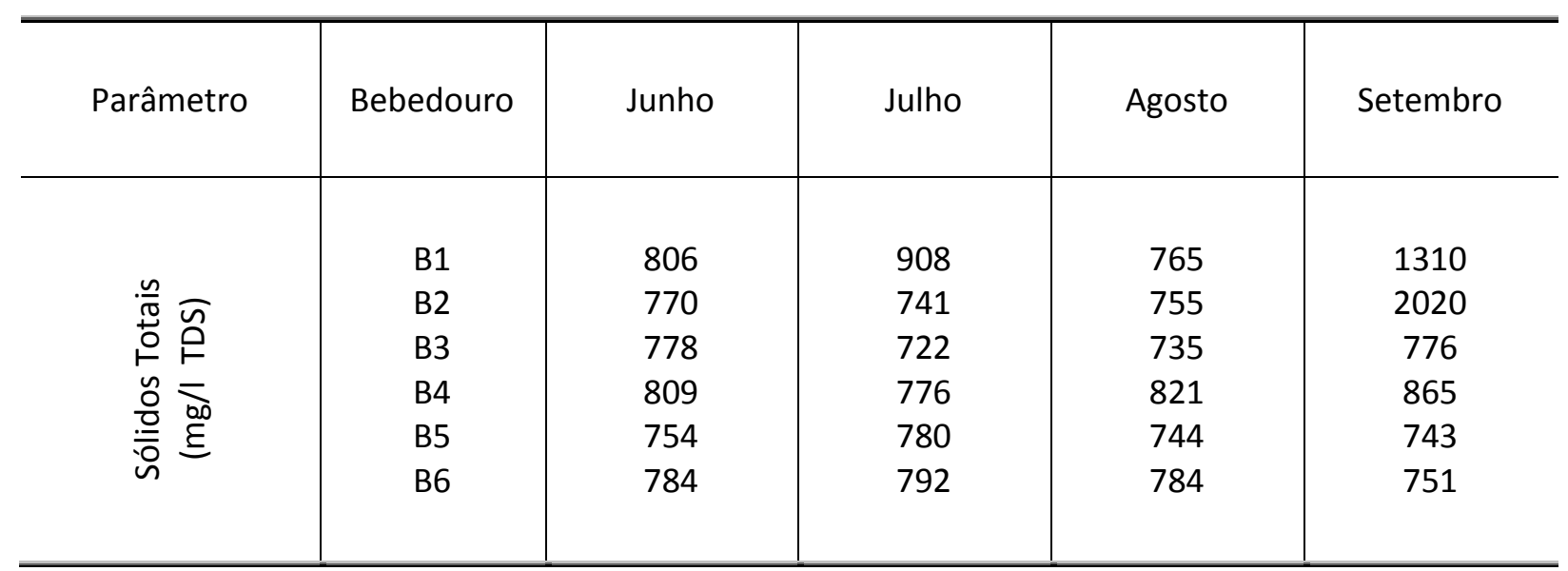


Destacam-se os bebedouros B1 e B2, que no mês de setembro, apresentaram valores muito altos.

Os sólidos totais dissolvidos na água indicam, indiretamente, outra forma de aferir a condutividade da água, uma vez que, a condutividade elétrica da água indica o nível de solubilidade de sais e outros compostos no meio aquático. Bagleyet al. (1997) realizaram estudos relacionando a esses parâmetros e reportaram que valores de 1.000 Partes por milhão (ppm) de sais totais dissolvidos, considerados baixos, possibilitam o fornecimento de água a qualquer espécie animal.

Por outro lado, concentrações de sais totais dissolvidos na água que variam de 1.000 a 4.999 ppm são consideradas satisfatórias para o fornecimento de ovinos e bovinos, mas, sem prejudicar o desempenho produtivo dos mesmos, podem causar diarréias temporárias ou ter pouca aceitação pelos animais não adaptados. Entre 5.000 a 6.999 ppm de sais totais dissolvidos a água pode também ser utilizada para ovinos e bovinos, porém seu consumo por animais em estágios avançados de gestação ou lactação deve ser evitado. De 7.000 a 10.000 ppm de sais totais dissolvidos o consumo deve ser evitado, mas em situações excepcionais essa água pode ser fornecida a animais adultos que não estejam em condições de estresse; entretanto, não deve ser fornecida a animais lactantes, gestantes, equinos, ovinos e animais jovens ou sujeitos a elevados níveis de estresse térmico ou perdas de água. A partir dessas concentrações de sais na água, a mesma não deve ser fornecida aos animais.

A condutividade elétrica é também um importante parâmetro indicador de qualidade da água e da salinidade. Os valores de condutividade aferidos na pesquisa estão apresentados na Tabela 5.

Tabela 5: Médias do parâmetro, condutividade $(\mathrm{mS} / \mathrm{cm})$, nos referidos meses e bebedouros.

\begin{tabular}{|c|c|c|c|c|c|}
\hline Parâmetro & Bebedouro & Junho & Julho & Agosto & Setembro \\
\hline 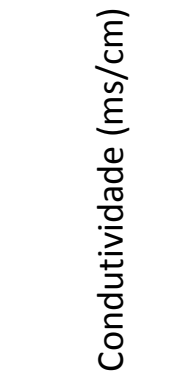 & $\begin{array}{l}\text { B1 } \\
\text { B2 } \\
\text { B3 } \\
\text { B4 } \\
\text { B5 } \\
\text { B6 }\end{array}$ & $\begin{array}{l}1,26 \\
1,20 \\
1,22 \\
1,27 \\
1,18 \\
1,22\end{array}$ & $\begin{array}{l}1,23 \\
1,21 \\
1,13 \\
1,21 \\
1,22 \\
1,24\end{array}$ & $\begin{array}{l}1,20 \\
1,18 \\
1,15 \\
1,28 \\
1,16 \\
1,22\end{array}$ & $\begin{array}{l}2,05 \\
3,24 \\
1,22 \\
1,35 \\
1,17 \\
1,18\end{array}$ \\
\hline
\end{tabular}

Vale ressaltar que foram encontrados altos valores de condutividade nos bebedouros B1 e B2, durante o mês de setembro. A condutividade também está diretamente relacionada aos sólidos totais dissolvidos, pois os sais dissolvidos fazem parte dessa composição. Dessa forma, como os referidos bebedouros apresentaram valores muito elevados de sólidos totais dissolvidos (Tabela 4), consequentemente, apresentaram um alto valor de condutividade. A condutividade elétrica na água que é oferecida para animais, quando se encontra em valores abaixo de 1,5 mS/cm são consideradas de qualidade excelente. Valores entre 1,5 e $5 \mathrm{mS} / \mathrm{cm}$ são satisfatórios para todas 
as classes de animais, porém, pode causar diarréia leve e temporária em animais não acostumados a águas com alta salinidade. (BAGLEY et al., 1997).

Runyan e Bader (1994) relataram que águas com teores de sais superiores a 8,0 a 11,0 dS/m devem ter seu fornecimento limitado aos ruminantes, incluindo os caprinos e ovinos. Águas com concentrações superiores a $11,0 \mathrm{dS} / \mathrm{m}$ são consideradas de alto risco para animais jovens, gestantes e lactantes, enquanto que água com concentrações de sais acima de $16,0 \mathrm{dS} / \mathrm{m}$ não oferecem condições de uso para as diversas espécies de animais.

\section{CONCLUSÃO}

Os resultados obtidos com este trabalho de pesquisa sobre a qualidade da água oferecida aos bovinos na fazenda-escola do IFRN-Ipanguaçu revelaram que os parâmetros analisados, de um modo geral, são satisfatórios. Contudo, é preciso ainda um manejo adequado da água (com renovação constante) e bebedouros que estejam dispostos não apenas em locais de fácil acesso aos animais, mas que também devam estar em locais cobertos ou arejados por copa de árvores.

\section{REFERÊNCIAS BIBLIOGRÁFICAS}

1. BAGLEY, CV, Kotuby-Amacher, J, Farrell-Poe, K. 1997. Analysis of water quality for livestock. Utah State University, Extension Service Bulletin No. AH/Beef /28. Disponível em< http://digitalcommons.usu.edu/cgi/viewcontent.cgi?article=1105\&context=extension_histall $>$ Acessoem 18/09/2015.

2. BRASIL. CONSELHO NACIONAL DO MEIO AMBIENTE. - CONAMA In: Ministério do Meio Ambiente. Resolução CONAMA no 357. Brasília. 2005.

3. DIAS, M. Qualidade da água e desempenho de bovinos. Informe técnico - Macal Nutrição Animal. 2006. 5p. Disponível em: http:// www.macal.com.br/uploads/1550915838.pdf. Acesso em 2015.

4. FRANSOLET, G.; VILLERS, G.; MASSCHELEIN, W.J. Influence of temperature on bacterial development in water. Ozone Science and Engineering. v. 7, n.3, p.205- 227, 1985.

5. GREIF, S. Conseqüências da pecuária para o meio ambiente. 2006. 2p. Disponível em: http:// www.guiavegano.com.br/vegan/forum/meioambiente. Acesso em 2015.

6. IEPEC. A importância da qualidade da água para vacas leiteiras. 2008. 5p. Disponível em: http://www.iepec.com/noticia/a-importancia-daqualidade- da-agua-para-vacas-leiteiras. Acesso em 2015.

7. NOGUEIRA, G.; NAKAMURA, C.V.; TOGNIM, M.C.B.; ABREU FILHO, B.A.; DIAS FILHO, B.P. Microbiological quality of drinking water of urban and rural communities, Brazil. Revista de Saúde Pública. São Paulo. v.37, n.2, 2003.

8. PALHARES, J.C.P. Água e avicultura: benefícios de um manejo correto. Nordeste Rural, $6 \mathrm{p}$. 2008. Disponível em: http://www.nordesterural.com.br/nordesterural/itenslst.asp?Instan celd=106Acesso em 2015.

9. PORTUGAL. Ministério da Agricultura e do Mar. Água de Qualidade Adequada na Alimentação Animal. Guia de Boas Práticas. 2014. 15p. Disponível em: http://www.dgv.min- 
agricultura.pt/xeov21/attachfileu.jsp?look_parentBoui=3016157\&att_display=n\&att_downlo $\mathrm{ad}=\mathrm{y}$. Acessoem: 21 ago. 2015.

10. RUNYAN, C.; BADER, J. Water quality for livestock and poultry. In: AYERS, R. S.; WESTCOT, D. W. Water quality for agriculture. Rome: FAO, 1976. 1994. (FAO. Irrigation and Drainage Paper, 29).

11. SANTOS, G.P. Água que mal-trata. Guia exclusive aves \& suínos. 3p. 2005. 